\title{
Piesis Sign Distinguishing Non-Ischemic Priapism in a Child
}

\author{
Dimitrios Sfoungaris, ${ }^{*}$ loannis Valioulis, loannis Patoulias
}

\author{
1st Department of Pediatric Surgery, Aristotelion University of Thessaloniki, General Hospital 'G. Gennimatas, Ethnikis Aminis 41, 54635 \\ Thessaloniki, Greece
}

\begin{abstract}
To differentiate between non-ischemic and ischemic priapism is imperative in clinical settings because the treatment of these two conditions is different and urgency of treatment too. Patient's history and Doppler color flow ultrasound contribute to the diagnosis. However, in situations where radiological investigations are not readily available in odd hours, a clinical test described in this report, the Piesis test, may be convenient. We herein report a 10-year-old boy with non-ischemic priapism diagnosed successfully with Piesis test.
\end{abstract}

Keywords: Priapism; Arterio-cavernous fistula; Erectile disorders; Piesis test

\begin{tabular}{ll}
\hline Correspondence $^{\star}$ : Dimitrios Sfoungaris, Ethnikis Aminis 41, 54635 Thessaloniki, Greece \\
$\begin{array}{ll}\text { E-mail: dsfounga@auth.gr } & \text { (c) 2018, Sfoungaris et al } \\
\text { Submitted: 24-12-2017 } & \text { Accepted: 07-02-2018 } \\
\text { Conflict of Interest: None declared } & \text { Source of Support: Nil }\end{array}$
\end{tabular}

This is an open-access article distributed under the terms of the Creative Commons Attribution License, which permits unrestricted use, distribution, and reproduction in any medium provided the original work is properly cited.

\section{INTRODUCTION}

Priapism is a prolonged full or partial penile erection unrelated to a sexual stimulus or persisting beyond stimulation, lasting over $4 \mathrm{~h}$.[1] There is a bimodal peak of incidence between 5-10 and 20-50 years of age, but with a higher peak affecting men in their fifth decade.[24] The reported incidence is $0.3-1.5$ per 100,000 male subjects per year, of which traumatic priapism accounts for $10 \%$ of cases.[4] There are no generalizable data on the prevalence of priapism in children, which is considered rare.[4]

Four types of priapism have been described: ischemic priapism (IP), non-ischemic priapism (NIP), stuttering priapism and neonatal priapism; caused by different etiologies and carrying a different prognosis. Reaching a prompt differential diagnosis between IP and NIP types is a matter of urgency because IP can cause damage to the corpora cavernosa and requires therapy on an emergent basis.[1-4] We report this uncommon case of NIP, which was successfully diagnosed on the basis of a clinical test.

\section{CASE REPORT}

A 10-year-old boy was referred to our service with complaints of persistent penile erection since the last 3 weeks. He had a history of blunt trauma over the perineal region six weeks back, caused by the saddle of his bicycle. Following two to three weeks of injury, he developed a penile erection, which was described as persistent and painless. On examination, his penis was erect, painless, relatively soft and non-tender. Perineum examination was normal. He didn't have any accompanying general or urinary symptoms. Hematological and urine panel were normal.

We performed a clinical test, the Piesis test, to ascertain whether it is high flow or low flow priapism. By applying moderate, but gradually increasing pressure on the whole shaft of the penis, much of the blood was 
expelled from the corpora cavernosa (CC) and the penis became flaccid. While still pressing on the penis, we applied pressure on the perineum over the right crus. For as long as pressure on the perineum was applied, the penis remained flaccid. When the pressure from the perineum was released, the penis resumed the erect position again (positive Piesis sign) in less than $10 \mathrm{sec}-$ onds. We repeated the same maneuvers while pressing over the left crus, but this time the penis became erect right away, even though the left perineum was still under pressure. We concluded that a vascular communication had developed at the right crus of the CC causing NIP. Color Doppler flow ultrasonography (CDFUS) performed through the perineum showed an abnormal space $2 \times 3 \mathrm{~mm}$ wide in the right crus, which represented an arterio-cavernous fistula forming a pseudoaneurysm and demonstrating pulsatile turbulent flow with a "yin-yang" pattern within (Figure 1). These findings confirmed the clinical diagnosis.

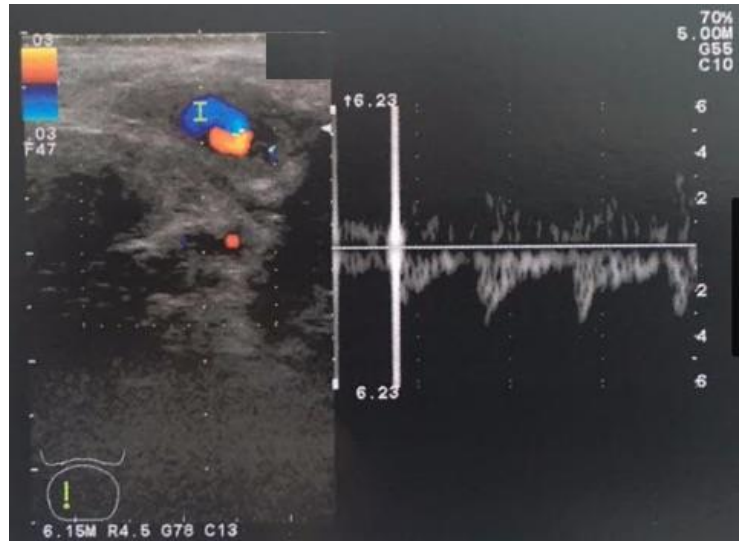

Figure 1: Color Doppler flow ultrasound of the right corpus cavernosum crus at the perineum. A turbulent flow with a "yin-yang" pattern within an abnormal space $2 \times 3 \mathrm{~mm}$ wide in the right crus, representing an arterio-cavernous fistula forming a pseudoaneurysm and an arterial type pulsatile spectrum.

After a discussion with the parents on the therapeutic options, they opted for an expectant treatment. Three weeks later, at follow-up, the clinical and CDFUS picture had not changed and we applied a fashioned brace, exerting pressure on the right side of the perineum, which was worn by the patient for about a month. Four months later, the penis was in moderate erection. Piesis sign was positive. Therapeutic options were discussed again with parents and they opted to use the fashioned brace for a few more months.

\section{DISCUSSION}

The most common type of priapism is IP. Its prevalence varies in different populations, proportionately to the incidence of sickle cell disease (SCD), since this disease is the most common cause of priapism $(65 \%)$. Leukemia may be another underlying cause $(10 \%)$ and also drug therapy and intracavernosal injections. In some cases, it is characterized as idiopathic.[4] Stuttering priapism (intermittent) has historically described as recurrent unwanted and painful erections in men or children with SCD.[5] These conditions cause adhesive interactions between erythrocytes, endothelial cells and leucocytes, leading to microvascular obstruction resulting in IP, also termed veno-occlusive or low-flow priapism.[4,5]

Stagnating blood in the CC is deoxygenated. A vicious cycle is activated, causing aberrant nitric oxide production, leading to smooth muscle necrosis. This leads to CC fibrosis, erectile disorders and penile distortion or shortening.[4] Studies have shown that ischemic priapism lasting longer than $24 \mathrm{~h}$ results in erectile disorder rates as high as $44-90 \%$.[3,6] IP is therefore considered a medical emergency.

The other type of priapism is the non-ischemic or highflow priapism (NIP) which is much rarer (10\%) and is mainly due to the trauma of the perineum or the penis causing vascular laceration, arterio-sinusoidal fistula, and high arterial blood flow into the CC. $[4,7]$ However, the high flow in the $\mathrm{CC}$ is accommodated by the venous drainage, no stasis ensues and the vicious cycle described above is not initiated. In contrast to IP, NIP is not considered a medical emergency.[4,7] Neonatal priapism is a rare entity of unknown cause in most cases, usually self-limited, with an estimated incidence of 1 in every 6673 newborn males.[8]

In cases of priapism, there are several clues from the patient's history and symptoms that help in the differential diagnosis between NIP and IP. A history of blood disease, especially SCD or leukemia, favors the diagnosis of IP. Hematological laboratory tests can confirm these diagnoses. A history of previous penile surgery or subtle perineal trauma, as seen in our case, suggests NIP. CDFUS can help identify an arterio-cavernous fistula with pseudo-aneurism and turbulent flow. A hard fully erect and painful penis is more characteristic for $I P$, while a softer and indolent one suggests NIP, as found in our case. $[1,4]$

Any laceration of a cavernous artery or arteriole can produce unregulated pooling of blood in sinusoidal space with a consequent erection. If the vascular laceration follows a blunt trauma, priapism is delayed until the post-traumatic clot is disrupted or cleared away, 
either by the healing process or by a nocturnal erection. Subsequently the disrupted vessels can communicate with CC and forms a pseudo-aneurism.[5] Typically, the onset of priapism is delayed by 3 to 7 days following trauma, however, it can be delayed for even months.[4] In our case, the patient developed symptoms two to three weeks after the injury.

The management of NIP should be expectant, at least initially. Many times the condition is self-limiting. Applying pressure on the site of the fistula might also help. Embolization or surgery are other options but a recurrence rate of $30-40 \%$ and risks of treatment-related erectile dysfunction cannot be ignored. Trans-corporal fistula ligation is only reserved where repeated embolization has failed, as it carries a higher risk of future erectile dysfunction.[1,4,5,9] Unfortunately, current literature is lacking in long-term outcome data.[2,4]

In this case, Piesis test helped us in clinching exact diagnosis which was later confirmed on doppler scan. The test is easy to perform in the emergency room, noninvasive and saves important time in decision making if a doppler scan is not available in time.

\section{Consent Statement}

Authors declared that they have informed written consent for publication of this case report including clinical material (photographs/video), and every effort will be made to conceal the identity of the patient although not fully guaranteed.

\section{Authors' Contribution}

Every author contributed equally in concept, drafting, literature review, and approval of final manuscript.

\section{REFERENCES}

1. Levy HR, Segal RL, Bivalacqua TJ. Management of priapism: an update for clinicians. Ther Adv Urol. 2014; 6:230244.

2. Roghmann F, Becker A, Sammon JD, Ouerghi M, Sun M, Sukumar S, et al. Incidence of priapism in emergency departments in the United States. J Urol. 2013; 190:1275-80.

3. Bennett N, Mulhall J. Sickle cell disease status and outcomes of African-American men presenting with priapism. J Sex Med. 2008; 5:1244-50.

4. Donaldson JF, Rees RW, Steinbrecher HA. Priapism in children: a comprehensive review and clinical guideline. J Pediatr Urol. 2014; 10:11-24.

5. Broderick GA, Kadioglu A, Bivalacqua TJ, Ghanem H, Nehra A, Shamloul R. Priapism: pathogenesis, epidemiology, and management. J Sex Med. 2010; 7:476e500.

6. Pryor JP, Hehir M. The management of priapism. Br J Urol. 1982; 54:751-4.

7. Hatzichristou D, Salpiggidis G, Hatzimouratidis K, Apostolidis A, Tzortzis V, Bekos A, et al. Management strategy for arterial priapism: therapeutic dilemmas. J Urol. 2002; 168:2074-7.

8. Kuwano AY, Cavalcante A, Costa-Matos A, Spanholi EF, Mascarenhas de Souza FM. Management in neonatal priapism: case and review. Urol Case Rep. 2017; 14:48-9.

9. Nabinger GB, Burttet LM, Lucena IR, Neto BS, Berger M, Rosito TE. Child non-ischemic priapism, a conservative approach: case report and updated review. J Pediatr Urol. 2013; 9:e99-101. 